\title{
Ethnic Cognition and Affect of British-Born Chinese Children
}

\author{
Virginia L. Lam ${ }^{1} \&$ Diane H. Tran ${ }^{1}$ \\ ${ }^{1}$ School of Psychology, University of East London, London, UK \\ Correspondence: Virginia L. Lam, School of Psychology, University of East London Stratford Campus, Water \\ Lane, London, E15 4LZ, UK. Tel: 44-208-223-2817. E-mail: v.lam@uel.ac.uk
}

Received: August 31, 2016

Accepted: October 20, $2016 \quad$ Online Published: January 11, 2017

doi:10.5539/jedp.v7n1p135

URL: http://dx.doi.org/10.5539/jedp.v7n1p135

\begin{abstract}
Little research has explored the ethnic cognition and affect of ethnic Chinese children from Britain and Europe, contrasting the established literature from North America. The present paper reports research which tested these developmental aspects among British-born ethnic Chinese children aged 5 to 10 years from London attending a Chinese supplementary language school. Children were given measures on categorisation skills, self- and other identifications, target matching (by gender and ethnicity), own preference and rejection, inferred preference and rejection of mothers, and trait attributions. Results showed that age was associated with categorisation skills and target matching, but not self- or other ethnic identifications on which children exhibited high performance. The majority of children preferred Chinese peers and rejected non-Chinese peers and inferred their mothers to do the same, and own and inferred mothers' rejection choices were related to each other. These findings are discussed in relation to previous research findings from other ethnic minority children including British Chinese children and ethnic Chinese children from elsewhere, and the theoretical and contextual factors that may impact British Chinese children's ethnic identity and attitudes.
\end{abstract}

Keywords: British-born Chinese children, ethnic cognition, ethnic affect

\section{Introduction}

Britain is widely seen as an ethnic diverse country and sociological and social policy literature has documented numerous challenges facing children that grow up with such diversity on these isles and its potential impact on identities and intergroup relations (Barron, 2007; Connolly, 1999, 2001; Connolly \& Hosken, 2006). Relatively little systematic quantitative research has investigated British children's ethnic cognition, however, with notable exceptions (Dai, McGregor, \& Williams, 2014; Davey, 1983; Lam, Guerrero, Damree, \& Enesco, 2011; Leman \& Lam, 2008; Milner, 1983; Norburn, 1983; Rutland, Cameron, Bennett, \& Ferrell, 2005).

The present paper reports a study that systematically investigated aspects of ethnic cognition and affect among British-born Chinese children aged 5 to 10 years. Hitherto, there has been only one published quantitative study of British Chinese (Scottish Chinese; Dai et al., 2014) children's identities and attitudes. This paucity is curious. With the increase in immigration from China to Britain (and other European countries) since three decades ago, the country has seen a steady population growth in its British-born younger generations with Chinese parentage (ONS, 2011). The relative lack of psychological research on British Chinese children's ethnic perception means that much of this review will draw on the literature of ethnic majority and minority children from Britain as well as elsewhere and sources about the British Chinese other than psychological literature.

The general consensus from the extensive research on ethnic and racial awareness of children from the US and Canada has been that children consciously notice those gross morphological differences between "basic" Black and White racial stimuli by the age of three years, and by the age of five most children can identify themselves by racial or ethnic labels (Katz \& Koftin, 1997). In ethnic diverse societies children are aware of such diversity and can self-identify even earlier, in particular those from minority groups (Katz, 1983; Ramsay, 1987). This is possibly due to the higher salience of ethnicity sensed by those who form a distinctive minority in their contexts (McGuire, McGuire, Child, \& Fujioka, 1978). This would mean that ethnic salience will diminish with increasing diversity in a given context, and this has been supported empirically (Dutton, Singer, \& Devlin, 1998; Ramsay, 1991). However, whether a group is the "majority" or a "minority" is not only a matter of numbers, but carries connotations of power status. In North American or European societies that are highly diverse nowadays, 
the "dominant" group in power is still the "White" population in terms of political and media representations and relative socioeconomic status, and this "status quo" may be subtly picked up by young minority children seeing their own group as the "other" in society (Cameron, Alvarez, Ruble, \& Ruligni, 2001).

The way in which children readily identify themselves and others as members of their racial or ethnic "ingroup" or "outgroups" and notice the status differentials between groups are further borne out by their attitudes towards such groups. Since the earliest work (Clark \& Clark, 1947) it has been reported that White children exhibit clear ingroup bias in the form of greater preference or liking towards White stimuli by the age of three. Furthermore, many non-White ethnic minority children in White-dominant countries (e.g., Aboud \& Skerry, 1983; Annis \& Corenblum, 1986) and even non-White majority children in countries or communities with few Whites (Bruce, Curtis, \& Johnson, 1998; Cramer \& Anderson, 2003) show obvious pro-White biases. Pro-White favouritism-often, if not always, concomitant with the rejection of, or negativity towards, non-White stimuli- has also been reported from middle through to later childhood in numerous studies (e.g., Aboud, 1988; Katz \& Kofkin, 1997; Leman \& Lam, 2008; Rutland et al., 2005).

Developmentally, an account that dominated for a considerable time is Social Cognitive Theory (SCT; Aboud, 1988), which proposed that cognitive development (along with certain social and motivational factors in a more minor role) contributes towards children's awareness of, and affect towards, members of different social groups. For the younger preoperational child, the key cognitive skill that is pertinent for person perception is perceptual categorisation, such as object classification, which requires the child being able to register both similarities and differences between group members along multiple dimensions (e.g., Bigler, Jones, \& Lobliner, 1997; Ramsey \& Myers, 1990). In this vein children evaluate group members in such a way where those similar to themselves are liked or seen as "good", and those more different are less liked or perceived as "bad", due to the focus on the self with perception dominated by affective processes featuring a fear of the unfamiliar (Aboud, 1988).

The notion that what is similar to the self is liked/good and what is different from it is disliked/bad also fits with the key premise of Social Identity Theory (SIT; Tajfel, 1981; Tajfel \& Turner, 1979), which proposes that mere categorisation is sufficient to create ingroup bias and outgroup prejudice. Self-categorisation with the ingroup is also an evaluative process where favourable comparisons with outgroups enhances one's social identity. This in part explains White children's ethnic attitudes as their ingroup compares favourably with others and non-White children's "misidentification" or White bias as reflecting their awareness of social norms and status imbalances. After improved representations of minorities in post-desegregation eras, increases in ingroup identification and favouritism versus earlier times in African-American children were found (Semaj, 1985; Spencer \& Markstrom-Adams, 1990). Still, to this day a substantial minority to a majority of non-White children in numerous studies, including some from Britain (Lam et al., 2011; Leman \& Lam, 2008), have found neutral or pro-White attitudes.

While one may expect the above identity and attitude pattern concerning ethnic minority groups to also hold for British Chinese children as a minority, "unfavourable" comparisons with the White majority might not as readily apply in this case. Chinese Americans (and other Asian Americans) were hailed as some of the "success stories" of immigrants for some time, with the younger generations cast as the academic achievers compared with other groups, including White Americans (Cheng \& Kuo, 2000; Fugligni, Witkow, \& Garcia, 2005). The featuring of Chinese people as a "model" minority is mirrored in Britain and can be attributed to similar factors. The Chinese in Britain are seen as highly self-dependent (due to their entrepreneurial beginnings; Parker, 1995), if relatively placid, isolated, and vulnerable (to discrimination; Pai, 2005). The educational success of British Chinese youth has been an interesting phenomenon given the "working-class" positioning of many families, who are argued to employ "family capital" (cultural, social and economic) and a "diasporic discourse" of valuing of education that promotes academic success, leading to a "transcending" of social class (Archer \& Francis, 2006). The synergy of positive motivation of the children and their parents' objectives are sometimes coined a form of "filial piety" that is responsible for the relatively high levels of achievement of less affluent Chinese pupils (Gates \& Guo, 2014).

The academic successes of British Chinese children with a backdrop of high familial expectations might come at a cost to their social representations. Chinese students in British education have been homogenised as "naturally good" or "not laddish" (if boys) or "passive" and "repressed" (if girls; Archer \& Francis, 2005). Such stereotypes are similar to those about Chinese Americans (e.g., Jackson Lewandowski, Ingram, \& Hodge, 1997; Spencer \& Markstrom-Adams, 1990). Experiences of isolation and discrimination were previously described about Chinese youth that led a "quiet" struggle with their identity while living an outwardly "British" lifestyle, or practicing the ethnic culture in private (Parker, 1995). By contrast, a recent study found that a dual (Scottish/Chinese) identity 
was expressed by Chinese children (aged 8-14 years) born in Scotland most of who showed a greater liking for, and attributed more positive traits to, Chinese versus Scottish people (Dai et al., 2015). Such recent findings are more in line with those from previous research on Dutch Chinese youth. Compared with other ethnic minorities, Dutch Chinese exhibited stronger ingroup identification and bias, which were attributed to their greater ingroup involvement and participation in cultural traditions (Verkuyten \& Kwa, 1996; Verkuyten, 1992). These factors are important to consider and contribute to making relevant predictions about our current sample.

The present study recruited its sample via the "supplementary" language school system that has, for a long time, provided tuition on native languages and cultures for many of Britain's ethnic minorities, often in the weekends. That the sample attended a Chinese language school indicates that they had relatively high levels of involvement with the ingroup and participation in cultural traditions. Based on these conditions and existing research findings about British Chinese children, our sample could be expected to exhibit high levels of ethnic awareness and self-identification (in cognition tasks) as well as ingroup biases (preference and trait attributions). The level of ethnic identification was expected to increase with age based on the pattern found about other British Chinese children (Dai et al., 2015). Ingroup bias should also increase with age, although the levels may "plateau", or even decline, towards later childhood, going by the premises of SCT concerning cognitive maturation of children at that stage, which purportedly moderates ingroup/outgroup perception. The children were also asked to infer their mothers' ethnic affect as a "significant other" (with an influence on children's own attitudes), where previous research has documented moderate associations between children's and perceived parental ethnic attitudes (Castelli, Carraro, Tomelleri, \& Amari, 2007; Lam et al., 2011). It is likely that British-born Chinese children's ethnic affect would therefore resemble their mothers' inferred affect.

\section{Method}

\subsection{Participants}

The sample consisted of 60 British-born Chinese children who attended a Chinese association language school with around 100 students in South London on Saturdays. So that age and gender differences could be analysed, children were sampled on the basis of their falling into three key age groups, 5-6 years $\left(M_{\text {age }}=5.65, S D_{\text {age }}=.49\right.$; $N=20), 7-8$ years $\left(M_{\text {age }}=7.40, S D_{\text {age }}=.50 ; N=20\right)$ and $9-10$ years $\left(M_{a g e}=9.55, S D_{\text {age }}=.51 ; \mathrm{N}=20\right)$, with an equal representation of boys and girls in each group. The parents gave written consent for their child to take part and the majority self-identified as "Chinese" $(40 \%)$ or "Chinese Vietnamese" (ethnic Chinese that migrated from Vietnam; 35\%) with a minority of "Hong Kong Chinese" (Chinese that migrated from Hong Kong; 20\%).

\subsection{Materials and Procedure}

Children were seen individually by a British Chinese experimenter in a quiet room in the supplementary school. She explained that they would play some "games" with photographs, drawings or word cards. The materials and tasks were adapted from previous studies with children of a similar or slightly younger age range (Guerrero et al., 2011; Lam et al., 2011). The social stimuli's (targets) ethnic groups were selected based on their numerical representations in the sample's neighbourhood (apart from the noticeable minority of Chinese residents, Black and White people formed the majority, $75 \%$ ). The tasks were given in the following order.

\subsubsection{Social Categorisation}

First, children were asked to sort photographs of unfamiliar children (targets). Photographs were used to permit realistic variations in features, but the targets were chosen on the basis that they represented features relatively typical of their ethnic grouping (Katz, Sohn, \& Zalk, 1975) and children primarily rely on such visible concrete information including skin colour and hair to categorise people (Aboud \& Skerry, 1983). Six photographs were chosen from a larger batch based on their comparable attractiveness ratings by adult judges. They showed three boys and three girls (one each of Black, White and Chinese ethnicity) all with smiling expressions differing in colour of clothing (orange or blue). The images were laid in front of each child, who was asked to sort them into two groups ("Can you put the ones that go together on one side...") and give his/her reason for the sorting. Then the images were shuffled and laid out again, and the child was asked to sort them using another criterion ("Sort them again, but in a different way from last time...") and give his/her reason for the second sorting.

\subsubsection{Target Matching}

To test children's attention to features denoting social categories, children were asked to pair a drawing with a photographed target, thereby "matching" their gender and ethnicity. Pictorial representations have been used in research examining ethnic cognition or affect with the advantage of being able to manipulate targets by features of interest (Augoustinos \& Rosewarne, 2001). In the trials the child was shown two drawings, one a Black child 
and the other Chinese (order of targets counterbalanced) of his/her own gender and four photographs (Black boy and girl, and Chinese boy and girl, as above). Each time the child was asked to choose the photograph on which the drawing was based ("Someone made this drawing of one of these children. Which is the child?").

\subsubsection{Preference and Rejection}

The six photographic targets above were shown again and children were asked to pick the one whom they would most like, or not like, to befriend ("which one of these children would you most like/most not like to be friends with?"). Each child was also asked for the reason for their choice each time as a check of their understanding.

\subsubsection{Inferred Preference and Rejection}

To explore the above measures in relation to children's inferences about their significant adult, children were asked which target their mother would prefer, or refuse, to invite to their own birthday party ("Which one of the children would your mum most like/not like to come to your birthday party?"). Each time the child was again asked for the reason for their choice as a check of their understanding of the questions.

\subsubsection{Trait Attributions}

This task involved presenting the three ethnic targets (Black, White and Chinese) matching the child's gender. She/he was asked to pick one that fitted each of a series of eight (four positive, four negative) traits (drawn from Augoustinos \& Rosewarne, 2001): good, smart, nice, good-looking, bad, stupid, ugly and dirty ("Which of these is the ... one?") in a randomised order. Children were also asked for the reason for their choice each time.

\subsubsection{Ethnic Identification}

To see whether children recognised the differences between the above ethnic groups and their common societal (British) labels, they were asked to slot the six photographs into three different boxes labelled "Black", "White" and "Chinese" accordingly (e.g., "Put the Black children's photos into this box...").

\subsubsection{Self-Identification}

In a way typically used for testing children's recognition of their own gender or ethnicity (Katz et al., 1975), the six targets were presented again and children asked to select the one that was "most like" them. As an indication of recognition of their group memberships, children were asked for the reason for their choice.

\section{Results}

An analysis comparing boys' and girls' responses on each measure was first run to check for gender differences, and no differences were shown in either ethnic cognition (social categorisation, ethnic and self-identifications, and matching) or affect (own and inferred mothers' preference and rejection and trait attributions) tasks. For the measures after social categorisation, responses were compared across age groups, and "social-cognitive levels" as derived from the social categorisation tasks (see below).

\subsection{Ethnic Cognition}

\subsubsection{Social Categorisation}

All, but three, children managed at least one logical sorting, even though the criteria for sorting were not limited to the set of social categories presented (gender, ethnicity or colour of clothing) - some ( $N=15$, first sort; $N=13$, second sort) children used the length of hair (the White girl target had shorter hair than the other girls) and facial expression (interpreting some targets to smile "bigger" or look "happier") deemed reasonable for sorting. Table 1 presents the criteria used by each age group for their first and second sorting. Children used ethnicity less frequently than other criteria for sorting, but no associations between criterion and age group were found. However, on first sorting the youngest group were less likely to sort correctly (5-6 years, $N=14)$ than the older groups (7-8 years, $N=18 ; 9-10$ years; $N=19 ; \chi^{2}=5.49, p=.03$, 1-tailed). Children also differed in their ability to sort twice (10 did not manage the second sort requiring a change of criteria). A coding system was devised so that those who managed no logical sorting were coded level 0 , those who managed one sorting were coded level 1 , and those who managed two were coded level 2 . The number of children falling into each level varied by age group $\left(\chi^{2}=7.61, p=.05,1\right.$-tailed $)$. All $(N=3)$ children at level 0 were 5 -6-year-olds, ten that achieved level 1 were split with two at age 9-10 and four each at 7-8 and 5-6 years, and level 2 was achieved by 13 at 5-6, 16 at 7-8 and 18 at 9-10 years of age. A Pearson's correlation test with age (in months) and sorting (social-cognitive) level found the correlation to be significant $(r=.30, p<.01 ; 1$-tailed $)$. 
Table 1. Criteria for social categorisation by age group (figures out of 20)

\begin{tabular}{llllll}
\hline Age group & Sorting & Ethnicity & Gender & Clothing & Other \\
\hline 5-6 years & First & 6 & 2 & 5 & 7 \\
& Second & 2 & 5 & 5 & 8 \\
7-8 years & First & 2 & 8 & 7 & 3 \\
& Second & 4 & 5 & 8 & 3 \\
9-10 years & First & 4 & 3 & 8 & 5 \\
\multirow{5}{*}{ Sample } & Second & 2 & 11 & 5 & 2 \\
& First & 12 & 13 & 20 & 15 \\
& Second & 8 & 21 & 18 & 13 \\
\hline
\end{tabular}

\subsubsection{Ethnic and Self-Identifications}

For identification of others, children had to sort all targets correctly into three labelled boxes ("White", "Black", "Chinese") to be marked "correct". All but four children (all 5-6-year-olds; $\chi^{2}=8.57, p<.01$, 1-tailed) correctly performed this task, and social-cognitive level was not associated with this performance. For self-identification, children had to choose the target of their own gender and ethnicity (Chinese) for a correct answer. All but two (both 5-6-year-olds; N.S.) were correct.

\subsubsection{Target Matching}

For these tasks, children had to match two target drawings (one Black and one Chinese) with the photographed targets by gender and ethnicity. All but five children (four 5-6-year-olds, one 7-8-year-olds; $\chi^{2}=5.67, p=.03$, 1-tailed) correctly matched the Chinese targets. Only two children (both 5-6-year-olds; N.S.) did not correctly match the Black targets. Performance in each task was not associated to social-cognitive level. Performances on both tasks (coded 0 for incorrect, 1 for correct) were combined to form a $0-2$ scale to explore the associations between matching and age in months, social-cognitive level and ethnic identification. Significant associations were found with age $(r=.24, p=.04 ; 1$-tailed $)$ and ethnic identification $(r=.46, p<.001 ; 1$-tailed $)$.

\subsection{Ethnic Affect}

\subsubsection{Own Preference and Rejection}

Table 2 shows the number of children from each age group that chose a White, Black or Chinese target as the child that they "most liked" or did "not like" to be "friends" with. Chi Square tests of independence found that the sample showed a preference for, and least rejection of, Chinese targets $\left(\chi^{2}=9.10, p=.01 ; \chi^{2}=17.10, p<.001\right.$, respectively, 1-tailed). The increase in Chinese preference towards age 7-8 years was not significant, and there were no associations between social-cognitive level and preference or rejection. Meanwhile, there was a significant association between children's preference and rejection $\left(\chi^{2}=14.34, p=.006,1\right.$-tailed). Table 3 lists the percentages of children that opted for each combination of ethnic targets. Post hoc tests found that children that preferred a Chinese target were less likely to reject a Chinese target $(p<.01)$.

Table 2. Target ethnicity of own and mothers' inferred preference and rejection by age group (figures out of 20)

\begin{tabular}{llccc}
\hline \multirow{2}{*}{ Own Preference } & & $5-6$ years & $7-8$ years & 9 -10 years \\
\cline { 2 - 2 } & White & 8 & 7 & 4 \\
\multirow{3}{*}{ Own Rejection } & Chinese & 5 & 1 & 5 \\
& White & 7 & 12 & 11 \\
\multirow{2}{*}{ Mothers Preference } & Black & 12 & 6 & 11 \\
& Chinese & 6 & 13 & 7 \\
\hline
\end{tabular}




\begin{tabular}{clccc}
\hline & Black & 3 & 4 & 1 \\
Mothers Rejection & Chinese & 13 & 10 & 16 \\
& White & 8 & 5 & 6 \\
& Black & 9 & 12 & 14 \\
& Chinese & 3 & 3 & 0 \\
\hline
\end{tabular}

\subsubsection{Mothers' Preference and Rejection}

Table 2 also presents the number from each age group that inferred that their mother would prefer, or refuse, to invite a White, Black or Chinese target to their home. Chi Square tests found the sample with an overall inferred preference for, and least rejection of, Chinese targets $\left(\chi^{2}=27.70, p<.001 ; \chi^{2}=21.10, p<.001\right.$; respectively, 1 -tailed). Post hoc tests confirmed that children were more likely to infer that their mother would prefer Chinese over White and Black targets $(p s<.001)$ as well as less likely to infer that she would reject Chinese over those targets $(p s<.01)$. No associations between inferred affect and age or social-cognitive level were reported. Like own affect, there was a significant association between inferred preference and rejection $\left(\chi^{2}=21.60, p<.001,1\right.$-tailed $)$. Table 3 also presents the percentages of children that inferred their mothers to prefer and reject each combination of targets. Generally, after children inferred that their mother would prefer a target of an ethnicity, they were less likely to infer that she would also reject a target of that ethnicity, and this was confirmed for each target ethnicity by post hoc tests (White, $p \mathbf{s}<.01$; Black, $p \mathbf{s}<.01$; Chinese, $p \mathbf{s}<.001$ ).

Table 3. Cross-tabulation of the target ethnicity of own preference/rejection, mothers' preference/rejection and own/mothers' rejection (figures in percentages)

\begin{tabular}{llllllllll}
\hline & \multicolumn{3}{c}{ Own preference/rejection } & \multicolumn{3}{c}{ Mothers' preference/rejection } & \multicolumn{3}{c}{ Own/ mothers' rejection } \\
\cline { 2 - 10 } & White & Black & Chinese & White & Black & Chinese & White & Black & Chinese \\
\hline White & 37 & 47 & 16 & 0 & 85 & 15 & 41 & 52 & 7 \\
Black & 82 & 0 & 18 & 63 & 0 & 38 & 19 & 73 & 8 \\
Chinese & 43 & 57 & 0 & 36 & 62 & 3 & 40 & 20 & 40 \\
\hline
\end{tabular}

Associations between children's own and inferred preference about mothers, and between their own rejection and inferred rejection about mothers, were also explored. Only the latter was found to be significant $\left(\chi^{2}=9.61\right.$, $p<.05,1$-tailed). Post hoc tests showed that children that rejected a Black target were more likely to also infer that their mothers would reject a Black target over a White or Chinese ethnic target $(p \mathbf{s}<.01)$.

\subsubsection{Trait Attributions}

Children chose a target that they felt best represented each of eight traits. Table 4 shows the number of children (out of 60, the sample) that chose each ethnic target for each trait. Children clearly favoured Chinese over other ethnic targets for positive traits, but for negative traits, the patterns were not significant apart from "bad", where Chinese targets received fewer nominations than either Black or White targets $(p s<.01,1$-tailed). There was no association between the attribution of any single trait and age or social-cognitive level. 
Table 4. Number of attributions (figures out of 60) on eight traits and mean positive/negative trait scores by target ethnicity

\begin{tabular}{lllll}
\hline & White & Black & Chinese & $\chi^{2} / F$ \\
\hline Good & 22 & 8 & 30 & $12.40^{* *}$ \\
Nice & 14 & 17 & 29 & $6.30^{*}$ \\
Good-looking & 19 & 9 & 32 & $13.30^{* * *}$ \\
Smart & 17 & 14 & 29 & $6.30^{*}$ \\
Bad & 23 & 29 & 9 & $9.70^{* *}$ \\
Dirty & 25 & 21 & 14 & 3.10 \\
Ugly & 18 & 22 & 20 & .40 \\
Stupid & 20 & 26 & 14 & 3.60 \\
Mean & 1.22 & .82 & 1.98 & $16.91 * * *$ \\
Positive & $(.94)$ & $(.79)$ & $(1.00)$ & \\
Mean & 1.42 & 1.63 & .93 & $4.43 * *$ \\
Negative & $(1.15)$ & $(1.10)$ & $(.97)$ & \\
\hline
\end{tabular}

${ }^{*} p<.05 ; * * p<.01 ; * * *^{*} p<.001$.

For further analysis, each trait attribution for a target ethnicity was coded 1 so that, for each child, both positive and negative traits were scored between 0 and 4 for each target ethnicity. Table 4 also shows the mean positive and negative attribution scores for each target ethnicity. It is clear that Chinese targets scored higher on positive, and lower on negative, attributions compared with White and Black targets, and this was confirmed by follow-up analyses (positive $p \mathbf{s}<.01$; negative $p \mathbf{s}<.05$ ). Finally, for each target ethnicity, the negative score was also subtracted from the positive score to form an overall trait attribution score for each child before the scores were entered to a repeated measures ANOVA, which showed a significant effect of trait attribution, $F(2,116)=11.00$, $p<.001$. Follow-up tests confirmed that Chinese targets $(M=1.05 ; S D=1.81)$ scored higher than both White $(M=-.20 ; S D=1.94 ; p<.01)$ and Black $(M=-.82 ; S D=1.68 ; p<.001)$ targets.

\section{Discussion}

The present study was conducted to examine British-born Chinese children's recognition of, and affect towards, ethnic ingroup and outgroup members. Only scarce psychological research (Dai et al., 2014) has systematically studied ethnic cognition and affect of British-born descendants from ethnic Chinese communities despite their growing demographic in the host country. We will first discuss the findings concerning ethnic cognition before those concerning ethnic affect.

\subsection{Ethnic Cognition}

We found that although our British Chinese sample aged 5 to 10 years were generally highly aware of their own and others' ethnic group membership (evident in their self- and ethnic identification and matching performance), they were relatively unlikely to spontaneously use ethnicity for categorising others (evident in their responses on the social categorisation task). The latter pattern is in line with the existing research findings of other British children (e.g., Lam et al., 2011) and those of children from most other countries (Aboud, 1988; Katz \& Kofkin, 1997). This finding also supports the idea that, provided that other categorical and non-categorical attributes are available, ethnicity does not offer the most salient characteristics for person perception (cf., Bennett et al., 1991; Ramsey \& Myers, 1990). This was the case in spite of the current context—being a study about ethnic cognition and affect conducted within a Chinese community school setting - which was considered to potentially raise the salience of ethnicity.

Although the youngest age group (5-6 years) were less "accurate" in ethnic cognition compared with their older counterparts (as evident in identification and matching performance), few age group differences were observed, apart from the relationship between age in months and overall matching performance. Similarly, no association between social-cognitive level and any other ethnic cognition area was found, perhaps unsurprisingly as social-cognitive level was related to age. Therefore, our finding is, at best, only roughly in line with that 
predicted by SCT, where children become more aware of, and accurate at distinguishing, persons from different groups that feature more subtle differences and identifying societal labelling closer to age 7 years, when cognitive maturity gives greater capacity for honing these categorisation skills (Aboud, 1988). That most of the younger children in this sample performed equally well at the ethnic cognition tasks as older children, and that their social-cognitive levels were only slightly lower than those of their counterparts, may also bear out the possibility that the social categorisation task (from which those levels were derived) was relatively simple (Bigler et al., 1997). In future research, more sophisticated methods for gauging multiple classification skills should be used.

The above findings may also reflect, as earlier reviewed, the ethnic salience in this context; the fact that parents sent their children to extracurricular schooling that educated them about their "mother tongue" and ethnic culture suggests that ethnicity was an important aspect of these children's upbringing. Furthermore, although the ethnic Chinese in Britain form a growing population, they are still a very small minority within the "ethnic minority" population (ONS, 2011) and this is likely to make their ethnicity salient in general (Dutton et al., 1998; Ramsay, 1991). Further studies may illuminate such contextual issues by sampling from more "normative" settings (such as state day schools - considering the very small numbers of Chinese pupils per school in that system) Chinese children as well as children from other ethnic groups with a wider range of ethnic identifications.

\subsection{Ethnic Affect}

Our findings showed a clear pattern of ingroup preference and least ingroup rejection (evident in own preference and rejection responses) as well as favourability towards the ingroup (evident in trait attributions) among British Chinese children. This is in line with previous findings from White (Aboud, 1988) and British Chinese children (Dai et al., 2014) and corresponds with the general premise of SIT. In addition, children's inferences about their mothers' affect resembled their own, again in line with existing findings (Castelli et al., 2007; Lam et al., 2011). Similar to ethnic cognition above, although there was greater ingroup preference from 7-8 years, there were no significant differences between age groups. There were also no associations between social-cognitive level and affect. Hence, our findings were not fully in support of the premises of SCT which denote that children's ethnic bias would "peak" towards around 7 years of age before declining towards late childhood where they pass stages from focusing on between-group differences and within-group similarities to noticing individual characteristics featuring within-group differences and between-group similarities with cognitive development (Aboud, 1988).

The findings that, regardless of age or socio-cognitive level, these British-born Chinese children preferred ethnic ingroup members as potential friends and judged them more favourably over outgroup members, expecting that their mothers would feel the same, might again bear out the salience of their ethnicity, since a young age, in both the supplementary school and family contexts. The latter context might also be borne out by the relationship between children's own and inferred mothers' rejection (where children were most likely to themselves reject, and to infer that their mothers would reject, a Black peer). That Black targets were also the least favoured group (evident in trait attributions) might betray the fact that, although Black people formed the numerically dominant ethnic minority group (after the White majority) in the neighbourhood, there are still a great deal of negative stereotypes attached to Black Britons, particularly younger Black males (Connolly, 1999; Lam \& Smith, 2009). Further research could include more measures of children's own and their parents' social stereotypes about different ethnic groups to ascertain this possibility.

Unlike the findings from recent research with other ethnic groups (Guerrero et al., 2011; Lam et al., 2011), this British Chinese sample's preference and rejection choices were related. While those studies found the inferences about mothers' preference and rejection to be associated, as was the case here, children's own choices were not. This, again, might be a result of the ethnic salient context (ingroup identity was likely strong), where children were relatively "logical" about both their own choices and inferences about the significant adult. Contexts where children vary more in their ethnic identification for further research may ascertain better the distinction between ingroup positivity and outgroup negativity, even though this distinction was reflected by trait attributions in this study as ingroup favourability was clear from children's responses to the positive, but not negative, traits.

The findings of this study mainly differed from those of studies with children of other British ethnic minorities (e.g., Lam et al., 2011; Leman \& Lam, 2008), in terms of the lack of White preference (or mothers' inferences). This might be in part due to the older sample in the current study (cf., preschoolers; Lam et al., 2011) or it could be that ingroup bias tends to consolidate through middle childhood though this has been largely the case only for White-majority children (Katz \& Koftin, 1997). The relatively "uniform" ingroup preference and favourability in British-born Chinese children might also reflect the sample's high levels of involvement with the ethnic ingroup 
(through the language school and family contexts), factors that are important for ingroup identification and bias (Verkuyten \& Kwa, 1992). Additionally, as a "model" minority that can compare favourably with other groups (Gates \& Guo, 2014) ingroup identification and bias are likely to be strong according to SIT.

\subsection{Limitations}

There are several limitations to this study that ought to be considered for future research, whether with British Chinese children or other ethnic groups. Our sample was drawn from the supplementary school sector primarily due to logistics (very few Chinese pupils in most British schools). The highly ethnic salient school context itself might have influenced children's responses to be more pro-ingroup than they might have been elsewhere. While the sector is still useful for future sampling, alternative testing locations and methods (such as at home or on campus and comparing explicit and implicit measures) may be used so that levels of identification and affect are more independent from the school context. Alternatively, children's cognition and affect may be assessed across different contexts systematically to explore the impact of context.

The ethnic "targets" in this study were represented by photographs of unfamiliar children to evoke affect towards different group members. Whether children's choices and evaluations reflect their "real-life" peer preference and attitudes or whether existing friendships or prior experiences with ethnic group members affect their judgments is unclear. Future studies may check the consistency between children's projected and real-life ethnic preference and intergroup attitudes by collecting data on the social group memberships of children's friends and their day school's demographics (which can impact opportunities for intra- and intergroup friendship formation). A fuller account for the ethnic cognition and affect of particular groups of children could only be ascertained by more studies with those children in different familial and educational settings with more detailed data on the specifics of those settings.

\section{Conclusion}

The current study systematically examined ethnic cognition and affect of British-born Chinese children aged 5 to 10 years. It found that the children did not tend to categorise people by ethnicity spontaneously, even though they were highly aware of ethnic group differences and labels, displayed clear ingroup biases, and deduced that their mothers would share such biases. Both psychological and contextual factors may explain such patterns, but more research is needed to study this under-researched, yet growing, ethnic group in Britain.

\section{Acknowledgments}

We thank the children, parents and teachers at the Chinese association supplementary language school (school is anonymised to protect privacy) who made this study possible, and our colleagues who commented on an earlier version of this paper before its submission.

\section{References}

Aboud, F. E. (1988). Children and prejudice. New York: Blackwell.

Aboud, F. E., \& Skerry, S. A. (1983). Self and ethnic concepts in relation to ethnic constancy. Canadian Journal of Behavioural Science, 1, 14-26. http://dx.doi.org/10.1037/h0080675

Annis, R. C., \& Corenblum, B. (1986). Effect of text language and experimenter race on Canadian children's racial self-identity. The Journal of Social Psychology, 126, 761-77. http://dx.doi.org/10.1080/00224545.1986.9713658

Archer, L., \& Francis, B. (2005). "They never go off the rails like other ethnic groups": Teachers' constructions of British Chinese pupils' gender identities and approaches to learning. British Journal of Sociology of Education, 26, 165-182. http://dx.doi.org/10.1080/0142569042000294156

Archer, L., \& Francis, B. (2006). Challenging classes? Exploring the role of social class within the identities and achievement of British Chinese pupils. Sociology, 40, 29-49. http://dx.doi.org/10.1177/0038038506058434

Augoustinos, M., \& Rosewarne, D. L. (2001). Stereotype knowledge and prejudice in children. British Journal of Developmental Psychology, 19, 143-156. http://dx.doi.org/10.1348/026151001165912

Barron, I. (2007). An exploration of young children's ethnic identities as communities of practice. British Journal of Sociology of Education, 28, 739-752. http://dx.doi.org/10.1080/01425690701610001

Bennett, M., Dewberry, C., \& Yeeles, C. (1991). A reassessment of the role of ethnicity in children's social perception. Journal of Child Psychology \& Psychiatry, 32, 969-982. http://dx.doi.org/10.1111/j.1469-7610.1991.tb01923.x 
Bigler, R. S., Jones, L. C., \& Lobliner, D. B. (1997). Social categorization and the formation of intergroup attitudes in children. Child Development, 68, 530-543. https://dx.doi.org/10.2307/1131676

Bruce, J., Curtis, H., \& Johnson, L. (1998). Social identity in young New Zealand children. New Zealand Journal of Psychology, 27, 21-27. from http://www.psychology.org.nz/wp-content/uploads/NZJP-Vol271-1998-4-Bruce.pdf

Cameron, J., Alvarez, J. M., Ruble, D. N., \& Fuligni, A. J. (2001). Children's lay theories about ingroups and outgroups: Reconceptualizing research on prejudice. Personality and Social Psychology Review, 5, 118-128. http://dx.doi.org/10.1207/S15327957PSPR0502_3

Castelli, L., Carraro, L., Tomelleri, S., \& Amari, A. (2007). White children's alignment to the perceived racial attitudes of the parents: Closer to the mother than father. British Journal of Developmental Psychology, 25, 353-357. http://dx.doi.org/10.1348/026151006X159851

Cheng, S. H., \& Kuo, W. H. (2000). Family socialisation of ethnic identity among Chinese American pre-adolescents. Journal of Comparative Family Studies, 31, 463-484. Retrieved from http://www.jstor.org/stable/41603713

Clark, K. B., \& Clark, M. P. (1947). Racial identification and preference in Negro children. In E. E. Maccoby, T. M. Newcomb, \& E. L. Hartley (Eds.), Readings in social psychology (pp. 602-611). London: Methuen.

Costigan, C. L., \& Su, T. F. (2004). Orthogonal versus linear models of acculturation among immigrant Chinese Canadians: A comparison of mothers, fathers, and children. International Journal of Behavioural Development, 28, 518-527. http://dx.doi.org/10.1080/01650250444000234

Connolly, P. (1999). Prejudice at play in primary pupils. Time Educational Supplement, 4348, 22-25.

Connolly, P. (2001). Qualitative methods in the study of children's racial attitudes and identities. Infant and Child Development, 10, 219-233. http://dx.doi.org/10.1002/icd.280

Connolly, P., \& Hosken, K. (2006). The general and specific effects of educational programmes aimed at promoting awareness of and respect for diversity among young children. International Journal of Early Years Education, 14, 107-126. http://dx.doi.org/10.1080/09669760600661260

Cramer, P., \& Anderson, G. (2003). Ethnic/racial attitudes and self-identification of black Jamaican and white New England children. Journal of Cross-cultural Psychology, 34, 395-416. http://dx.doi.org/10.1177/0022022103034004002

Dai, Q., McGregor, E., \& Williams, J. (2015). Being Chinese or being Scottish: National identification and intergroup attitudes of British born Chinese children. European Journal of Developmental Psychology, 12, 282-296. http://dx.doi.org/10.1080/17405629.2014.1002083

Davey, A. G. (1983). Learning to be prejudiced. London: Edward Arnold.

Dutton, S. E., Singer, J. A., \& Devlin, A. S. (1998). Racial identity of children in integrated, predominantly White, and Black schools. The Journal of Social Psychology, 138, 41-53. $\mathrm{http}: / / \mathrm{dx}$. doi.org/10.1080/00224549809600352

Fugligni, A. J., Witkow, M., \& Garcia, C. (2005). Ethnic identity and the academic adjustment of adolescents from Mexican, Chinese, and European backgrounds. Developmental Psychology, 41, 799-811. http://dx.doi.org/10.1037/0012-1649.41.5.799

Gates, P., \& Guo, X. (2014). How British-Chinese parents support their children: A view from the regions. Educational Review, 66, 168-191. http://dx.doi.org/10.1080/00131911.2013.768958

Guerrero, S., Enesco, I., \& Lam, V. L. (2011). Racial awareness, affect and sorting abilities: A study with preschool children. Anales de Psicologia, 27, 639-646. Retrieved from http://revistas.um.es/analesps/article/view/135201

Jackson, L. A., Lewandowski, D. A., Ingram, J. A., \& Hodge, C. N. (1997). Group stereotypes: Content, gender specificity, and affect associated with typical group members. Journal of Social Behavior and Personality, 12, 381-196.

Katz, P. A. (1983). Developmental foundations of gender and racial attitudes. In R. L. Leahy (Ed.), The child's construction of social inequality (pp. 41-78). New York: Academic Press. 
Katz, P. A., \& Koftin, J. A. (1997). Race, gender and young children. In S. S. Luthar, J. A. Burack, D. Cicchetti, \& J. R. Weisz (Eds.), Developmental psychopathology: Perspectives on adjustment, risk, and disorder (pp. 51-74). New York: Cambridge University Press.

Katz, P. A., Sohn, M., \& Zalk, S. R. (1975). Perceptual concomitant of racial attitudes in urban grade-school children. Developmental Psychology, 11, 135-144. https://dx.doi.org/10.1037/h0076446

Lam, V. L., Guerrero, S., Damree, N., \& Enesco, I. (2011). Young children's racial awareness and affect and their perceptions of mothers' affect in a multiracial context. British Journal of Developmental Psychology, 29, 842-864. http://dx.doi.org/10.1348/2044-835X.002013

Lam, V. L., \& Smith, G. (2009). African and Caribbean adolescents in Britain: Ethnic identity and Britishness. Ethnic and Racial Studies, 32, 1248-1270. http://dx.doi.org/10.1080/01419870802298421

Leman, P. J., \& Lam, V. L. (2008). The influence of race and gender on children's conversations and playmate choices. Child Development, 79, 1329-1343. http://dx.doi.org/10.2307/27563555

McGuire, W. J., McGuire, C. V., Child, P., \& Fujioka, T. (1978). Salience of ethnicity in the spontaneous self-concepts as a function of one's ethnic distinctiveness in the social environment. Journal of Personality and Social Psychology, 15, 511-520. http://dx.doi.org/10.1037/0022-3514.36.5.511

Norburn, V. (1983). Ethnic preferences in young children and in their adolescence in three London districts. Human Relations, 36, 309-344. http://dx.doi.org/10.1177/001872678303600401

ONS $\backslash:$ Office for National Statistics. (2011). The United Kingdom Census 2011. London: ONS.

Parker, D. (1995). Through different eyes: The cultural identities of young Chinese people in Britain. Aldershot: Avebury Press.

Ramsay, P. G. (1987). Young children's thinking about ethnic differences. In J. S. Phinney, \& M. J. Rotheram (Eds.), Children's ethnic socialisation: Pluralism and development (pp. 56-72). Newbury Park, CA: Sage.

Ramsay, P. G. (1991). The salience of race in young children growing up in an all-White community. Journal of Educational Psychology, 83, 28-34. http://dx.doi.org/10.1037/0022-0663.83.1.28

Ramsey, P. G., \& Myers, L. C. (1990). Salience of race in young children's cognitive, affective, and behavioural responses to social environments. Journal of Applied Developmental Psychology, 11, 49-67. http://dx.doi.org/10.1016/0193-3973(90)90031-E

Semaj, L. T. (1985). Afrikanity, cognition, and extended self-identity. In M. B. Spencer, G. K. Brookins, \& W. R. Allen (Eds.), Beginnings: The social and affective development of black children (pp. 185-200). Hillsdale, NJ: Erlbaum.

Spencer, M. B., \& Markstrom-Adams, C. (1990). Identity processes among racial and ethnic minority children in America. Child Development, 61, 290-310. http://dx.doi.org/10.2307/1131095

Tajfel, H. (1981). Human groups and social categories: Studies in psychology. Cambridge: Cambridge University Press.

Tajfel, H., \& Turner, J. C. (1979). An integrative theory of intergroup conflict. In W. G. Austin, \& S. Worchel (Eds.), The social psychology of intergroup relations (pp. 33-47). Monterey, CA: Brooks/Cole.

Verkuyten, M. (1992). Ethnic group preferences and the evaluation of ethnic identity among adolescents in the $\begin{array}{llllll}\text { Netherlands. The Journal of Social Psychology, 32, } & \text { 750. }\end{array}$ http://dx.doi.org/10.1080/00224545.1992.9712104

Verkuyten, M., \& Kwa, G. A. (1996). Ethnic self-identification, ethnic involvement, and group differentiation among Chinese youth in the Netherlands. The Journal of Social Psychology, 136, 35-48. http://dx.doi.org/10.1080/00224545.1996.9923027

\section{Copyrights}

Copyright for this article is retained by the author(s), with first publication rights granted to the journal.

This is an open-access article distributed under the terms and conditions of the Creative Commons Attribution license (http://creativecommons.org/licenses/by/4.0/). 